Article

\title{
Crossing the Great Divide: Bridging the Researcher-Practitioner Gap to Maximize the Utility of Remote Sensing for Invasive Species Monitoring and Management
}

\author{
Kelsey Parker 1,2,*iD, Arthur Elmes ${ }^{3}$ (D), Peter Boucher ${ }^{4}$, Richard A. Hallett ${ }^{5}$, John E. Thompson ${ }^{6}$, \\ Zachary Simek ${ }^{7}$, Justin Bowers ${ }^{1}$ and Andrew B. Reinmann ${ }^{1,2,8}$
}

Citation: Parker, K.; Elmes, A.; Boucher, P.; Hallett, R.A.; Thompson, J.E.; Simek, Z.; Bowers, J.; Reinmann, A.B. Crossing the Great Divide: Bridging the Researcher-Practitioner Gap to Maximize the Utility of Remote Sensing for Invasive Species Monitoring and Management. Remote Sens. 2021, 13, 4142. https://doi.org/ $10.3390 /$ rs13204142

Academic Editors: Ioannis Gitas and Thomas Katagis

Received: 10 September 2021

Accepted: 13 October 2021

Published: 16 October 2021

Publisher's Note: MDPI stays neutral with regard to jurisdictional claims in published maps and institutional affiliations.

Copyright: (c) 2021 by the authors Licensee MDPI, Basel, Switzerland. This article is an open access article distributed under the terms and conditions of the Creative Commons Attribution (CC BY) license (https:// creativecommons.org/licenses/by/ $4.0 /)$
1 Environmental Sciences Initiative, The City University of New York Advanced Science Research Center, New York, NY 10031, USA; jbowers1@gc.cuny.edu (J.B.); areinmann@gc.cuny.edu (A.B.R.)

2 Earth and Environmental Sciences, Graduate Center, The City University of New York, New York, NY 10016, USA

3 School for the Environment, University of Massachusetts Boston, Boston, MA 02125, USA; arthur.elmes@umb.edu

4 Department of Organismic and Evolutionary Biology (OEB), Harvard University, Cambridge, MA 02138, USA; pboucher@g.harvard.edu

5 Forest Service Northern Research Station, New York City Urban Field Station, Bayside, New York, NY 11359, USA; Richard.Hallett@usda.gov

6 Catskill Regional Invasive Species Partnership (CRISP), Catskill Center, Arkville, NY 12406, USA; jthompson@catskillcenter.org

7 The Nature Conservancy, Keene Valley, NY 12943, USA; zachary.simek@tnc.org

8 Department of Geography and Environmental Science, Hunter College, New York, NY 10065, USA

* Correspondence: kparker@gradcenter.cuny.edu

Abstract: Invasive species are increasingly present in our ecosystems and pose a threat to the health of forest ecosystems. Practitioners are tasked with locating these invasive species and finding ways to mitigate their spread and impacts, often through costly field surveys. Meanwhile, researchers are developing remote sensing products to detect the changes in vegetation health and structure that are caused by invasive species, which could aid in early detection and monitoring efforts. Although both groups are working towards similar goals and field data are essential for validating RS products, these groups often work independently. In this paper, we, a group of researchers and practitioners, discuss the challenges to bridging the gap between researchers and practitioners and summarize the literature on this topic. We also draw from our experiences collaborating with each other to advance detection, monitoring, and management of the Hemlock Woolly Adelgid (Adelges tsugae; HWA), an invasive forest pest in the eastern U.S. We conclude by (1) highlighting the synergies and symbiotic mutualism of researcher-practitioner collaborations and (2) providing a framework for facilitating researcher-practitioner collaborations that advance fundamental science while maximizing the capacity of RS technologies in monitoring and management of complex drivers of forest health decline such as invasive species.

Keywords: remote sensing; invasive species; researcher-practitioner gap; hemlock woolly adelgid; saltcedar

\section{Introduction}

The global transport of goods and people has facilitated widespread invasions of non-native organisms, often with substantial ecological and economic consequences [1-3]. Some of these non-native species have attributes that allow them to proliferate without the predators, pathogens, competitors, or other mechanisms of population control that exist in their native range. If these organisms are able to become established and threaten populations of native species, the organisms are considered "invasive". Approximately $37 \%$ of all invasive species globally were introduced to their new range between 1970 and 
2014 and there is no sign of this trend slowing [4]. The Center of Invasive Species and Ecosystem Health lists over 300 invasive insects and over 1600 invasive plants across the United States (U.S.) alone. These invasive species can have severe ecological and economic consequences. For example, there is evidence that invasive species have been altering the evolutionary trajectory of native species through competitive exclusion, hybridization, predation, and sometimes extinction [5]. It is estimated that invasive pests and pathogens cause billions of dollars in economic damages each year in the U.S. alone from factors such as timber loss, decline in residential property value, and municipal costs to treat, remove, or replace trees in parks or on city streets $[6,7]$. Because of these impacts, invasive species are of high concern to both research and practitioner communities. Here, we define researchers as anyone who conducts scientific research as a large part of their job description and is publishing their results in peer-reviewed scientific journals. By contrast, we define practitioners as anyone whose primary work objectives are focused on ecosystem management (e.g., invasive species control and timber harvesting). We do not distinguish these groups based on who their employer is and both groups may be employed by academic or government institutions, non-profit organizations, or forprofit companies. Although both communities place a high priority on identifying new occurrences of invasive species, researchers and practitioners often do not work together. This lack of collaboration can result in lost opportunities to take advantage of the synergistic areas of expertise that researchers (e.g., remote sensing expertise) and practitioners (e.g., field surveys, management, and local knowledge) can bring to bear.

Mapping the distribution and impacts of invasive species are critical to advancing our understanding of their ecological consequences, our management capacity, and our ability to assess the efficacy of control efforts. In situ field surveys are a commonly used approach to mapping the distribution of invasive species. While this mapping tactic can be highly effective for the places visited, it is also costly, time consuming, and labor intensive. Consequently, relying on field surveys alone is often inefficient and impractical for assessments of invasive species in remote areas and/or with large spatial extents. Remote sensing (RS) can help to overcome some of the challenges associated with field surveys and holds substantial promise as a tool for improving detection and mapping of invasive species and their impacts on forest ecosystems [8,9]. Oftentimes, the invasive pests and pathogens of concern in forest ecosystems (e.g., Hemlock Woolly Adelgid (HWA; Adelges tsugae), Gypsy Moth (Lymantria dispar), and Dutch Elm Disease (Ophiostoma ulmi and Ophiostoma novo-ulmi)) are too small to be directly detected using satellite imagery, and instead proxies such as changes in ecosystem health and vegetation phenology are often used to aid detection [10-13]. Because of the larger size of many trees, spectral signatures, leaf phenology, or texture can be used to distinguish native vs. invasive tree species (e.g., invasive Norway maple vs. native oak trees in the northeastern U.S.) [14]. Most studies report using some sort of vegetation index to measure decline in health associated with invasive pests and pathogens or to look at phenological differences in seasonality and interannual variations in leaf phenology which can occur as non-native plant species invade. Some examples include the Normalized Difference Vegetation Index (NDVI [15]), Moisture Stress Index (MSI [16]), Leaf Area Index (LAI [17]), and Tasseled Cap Transformation [10].

The methods used to detect invasive species must be adjusted to reflect the lifecycle, habitat requirements, and impacts on native vegetation of the particular species of concern [18]. There are a wide variety of satellite-based sensors collecting images across the globe with different spatial, temporal, and spectral resolutions and each sensor has its strengths and drawbacks. Commercial satellites such as Maxar's WorldView and the Planet Labs' DOVE constellation were first launched in 2007 and 2013, respectively, and offer high spatial (1-3 m) and temporal (daily return) resolutions but can be costly to obtain. In contrast, the Moderate Resolution Imaging Spectrometer (MODIS), a U.S. National Aeronautics and Space Agency (NASA) satellite with freely available data, has high temporal resolution collecting images daily since 2000, but at moderate to coarse spatial resolution 
(250 m-1 km). The joint U.S. Geologic Survey (USGS)-NASA Landsat satellites and the European Space Agency's (ESA) Sentinel-2 satellites provide relatively high spatial resolution (10-30 m), but moderate temporal resolution (5-16 days). Landsat-1 was launched in the early 1970s, with seven subsequent launches having taken place since then. Sentinel-2, which consists of an identical pair of satellite sensors, was launched in 2015 and 2017. For some studies, having a longer time series of data can be useful for detecting change over time, but it is important to consider sensor drift and cross-sensor calibration issues in the case of a series of similar sensors, such as the Landsat 1-8 series. Other RS technologies such as Synthetic Aperture Radar (SAR) can overcome the problem of cloud cover-a common limitation with other RS technologies-and provide information on ecosystem structural characteristics to aid in invasive species detection and research. For example, SAR has been used to monitor the invasive species, American bramble (Rubus cuneifolius), which has become a major threat to native flora in South Africa [19].

By quantifying declines in plant and/or ecosystem health or detecting spatial and temporal differences in leaf phenology, researchers can use satellite RS imagery in conjunction with field validation data to model the spatial distribution of the target invasive species. Ideally, these models would be used to inform practitioners of the possible locations of targeted invasives to enhance their mapping and management efforts. Although researchers have for decades been developing RS models for numerous invasive species of concern including the insects HWA [10,20,21] and Gypsy Moth [22], and shrubs such as Amur honeysuckle (Lonicera maackii) [23], these products are rarely used by practitioners. These distribution maps can also help inform how other aspects of environmental change (e.g., climate change, land cover change, nutrient deposition) could influence the rate of spread and ecological impacts of invasive species [24]. Integrating data on important predictive variables including air temperature, forest composition, topography, soil type, and resource availability can further inform where an invasive species may be or could spread to. Field data are essential in RS studies to calibrate and validate models but can be challenging and costly to obtain across the large geographic areas typically impacted by invasive species. Collaborations between practitioners and researchers can be mutually beneficial by providing researchers with valuable field data to calibrate and validate models while providing practitioners with improved species distribution models and maps of the ecological impacts of invasive species of concern, which will allow efficient use of scarce resources.

As our climate and landscapes continue to change and globalization intensifies, the introduction, spread, and impacts of non-native pests and pathogens will undoubtedly increase. Practitioners and researchers working together to leverage each other's resources and expertise can greatly benefit our collective knowledge on invasive species while increasing the broader utility and application of RS technologies for controlling their spread. The research community has made great strides in using satellite RS to detect changes in the health and condition of forest ecosystems related to invasive species [25-27]. However, reproducing RS methods can be challenging, particularly outside of research communities, and model development can often be limited by the availability of relevant field data, which is necessary for model parameterization and assessment. Often there is a mismatch between the objectives of the scientific community, the results they publish, and the needs of practitioners. For example, Kudzu (Pueraria montana) is a widespread and common invasive plant species of high concern among practitioners across much of the eastern U.S., but there are few field- or RS-based quantitative studies of this woody vine [28]. Working together to ensure that researchers are answering questions that are relevant to the needs of practitioners while also developing and implementing uniform field assessment methods so the data can be used to support development and improvement of RS-based models could help both researchers and practitioners advance their common goal of monitoring and controlling invasive species and their ecological impacts.

The knowing-doing gap in ecology - the divide between what researchers focus on and what practitioners need to make informed management decisions-has been 
well documented from both researcher and practitioner perspectives [29,30]. However, analogous discussions on how this gap could be closed in the field of invasive species monitoring, specifically using RS, are not as well documented. Here, our team of researchers and practitioners summarize the peer-reviewed literature on the divide between researchers (ecology and remote sensing scientists) and ecology practitioners, highlight some of the challenges and mutual benefits of researcher-practitioner collaborations, and present a new framework for fostering these collaborations. Using the published literature and our own experiences collaborating with researchers and practitioners, we provide recommendations for how these communities can come together. Our aim is to demonstrate how bridging the divide can advance understanding and monitoring of invasive species using RS tools and show how cross-disciplinary partnerships could be mutually beneficial to the objectives of both parties. While our focus is on the topic of invasive species in forest ecosystems, because these efforts seek to fundamentally characterize different aspects of forest condition, the approaches to collaboration that we describe are broadly relevant to many topics related to forest health monitoring.

\section{Materials and Methods}

We reviewed the scientific literature to summarize the challenges and needs of practitioners and researchers as well as barriers to collaboration. We drew from papers published between the years 1980 and 2021. Our starting year was selected as this is the earliest period in time when satellite RS may have been applied to ecological research. We identified papers in Google Scholar using the search terms "Academic-Practitioner Gap AND Ecology", "Knowing-Doing Gap AND Ecology". "Ecology" was also replaced with "Biology" in some searches to include invasive species biologists and conservationists. Other search terms included "Community Science", "Civic Science", and "Citizen Science", "Open-Source Data Ecology", "Invasive Species AND Remote Sensing", "Remote Sensing AND Saltcedar", and "Hemlock Woolly Adelgid AND Remote Sensing". Variations of search terms were also included. Criteria for paper selection included relevancy to the topic or field of study.

\section{Results}

In total, we found 87 papers that met our criteria and $60 \%$ were published since 2006. Our literature review indicated that, although research focusing on RS applications for invasive species mapping is growing, it is often not directly applicable or accessible by practitioners. This suggests the need to expand on this area, in an effort to build bridges between research and practice. The literature also revealed the importance of involving graduate students as one means of bridging the divide between researchers and practitioners. HWA is a widely distributed invasive forest pest in the eastern U.S. and is of pressing concern to both researchers and practitioners. Our team has extensive experience with HWA and we use as a case study to highlight the current challenges of bridging researcher and practitioner communities. We also use saltcedar as a case study because our literature review pointed to this species as a key example of the potential utility of RS for long-term monitoring and restoration efforts by practitioners.

\subsection{Remote Sensing Applications to Invasive Species Mapping and Management \\ 3.1.1. Mismatches}

Collaborations between practitioners and researchers have great potential for developing new RS products and novel approaches to invasive species research and monitoring [31]. However, many obstacles still exist. Some of these obstacles are logistical, for example sharing large databases and workflows can be challenging [32]. Other obstacles stem from differences in fields of study. Even within scientific communities RS researchers and ecologists are often in separate departments and use different jargon, spatial scales, tools, and methods in their work [31]. The gap between RS researchers and practitioners is even wider. In order to bridge the gap between these communities, collaboration and, in some cases, compromise, are necessary to realize the full potential of these partnerships. Researchers 
who aim to inform management with their research can facilitate and build long-term collaborations and networks with practitioners which can help transition research findings into application. These collaborations are essential in all steps of research, but especially in developing questions and methods $[30,33,34]$. Practitioners and researchers monitoring invasive species and their impacts are simultaneously, but often independently responding to the threat of invasive species, which can lead to mismatches in data availability and needs, repetition of effort, and limited integration of RS products.

One study surveyed practitioners to understand what applied and basic research topics were of highest priority to them and then compared their responses to the topics covered in recently published field ecology literature [35]. They found that topics such as early detection, seed banks, dispersals, and lifecycles of invasive species were underrepresented in the literature while topics relating to biocontrol and resource manipulation were published on more than practitioners indicated they desired knowledge on the topic. RS studies often address the issue of mapping early outbreaks and even dispersal patterns in some cases [36]. Practitioners have also expressed a desire for research monitoring restoration efficacy over multiple years [37] and some RS studies have begun to monitor restoration across large areas [38-40]. However, practitioner integration of RS models and products into their work is still limited, pointing to a need for collaborations between researchers and practitioners.

Effective collaborations operate as a sort of symbiotic mutualism, where each group contributes their expertise and data that is collected as part of their routine workflow. In the case of invasive species early detection/monitoring for forested landscapes, field data is an essential part of RS model development and is needed for calibration, training, and validation of remotely sensed imagery. Historically, RS model development relied heavily on field data. However, some studies utilize the highest spatial and temporal resolution remote sensing data available to circumvent a lack of field data, but this option is not always possible, often requires expensive RS products, and the lack of field validation can limit the effectiveness of a model. Meanwhile, practitioner groups regularly collect field data and work to monitor and learn more about the natural histories and ecological impacts of invasive species but are eager for more efficient and cost-effective ways to detect outbreaks. By working together to meet each other's needs, the separate workflows of researcher and practitioners can be combined (Figure 1) to prevent redundancy in each group's efforts, increase field data availability for RS model development, and make RS products more relevant and tangible to practitioners and not just research exercises.

\subsubsection{Basic Data Needs and Satellite Imagery Obstacles}

In order to effectively map and monitor an invasive species, researchers need to have knowledge of the natural histories (e.g., lifecycle and habitat requirements) of the invasive species and the ways they impact the ecosystems they invade. Because of differences in the ecology of invasive species and the ways they impact forest ecosystems, each invasive species may require different approaches to modeling. Information on the ecology and natural history of a particular invasive species that is often needed to help develop robust models could come from practitioners who observe these species and their ecological impacts in the field. Practitioners often collect data from relatively small spatial extents, which may increase the likelihood that information gleaned from these data is biased by nuanced local conditions. However, this too can be beneficial to the development of remote sensing models because along with data sets from practitioners in other locations these data broaden the suite of conditions used to inform models. Perhaps one of the most impactful ways to improve detection of invasive species by both researcher and practitioner communities is to develop spatially explicit maps of the native species or forest type impacted by a particular invasive species of concern [41]. These maps would enable researcher and practitioner field crews to take a more informed and targeted approach to field surveys and application of RS models. Information on the severity of an invasive species infestation and its ecological impacts are crucial to inform practitioner response. If 
the infestation intensity is low, practitioners may choose to respond rapidly with treatment methods. However, if infestation intensity is high, containment rather than eradication may be the chosen management objective. Including factors that may contribute to the ecological impacts of infestation can help practitioners prioritize treatment. For example, hemlock trees infested with HWA are more vulnerable to drought, so stands in dry areas, such as those on steep and/or south and southwest facing slopes, are likely to be more severely impacted by HWA than others with wetter soil conditions [42-46].

The data needs of RS researchers often vary as a function of the species of concern and the research objectives delineated. Most invasive species impacting forest ecosystems lie below the canopy (e.g., insects, vascular plants, and pathogens), which means that RS is measuring the impact of the species on different metrics of forest health as an indication of its presence. For this reason, relying on satellite RS using surface reflectance alone can be challenging when impacts to the top of the canopy are not immediately evident and/or the canopy is particularly dense. Microwave RS and SAR can get around some of the challenges of surface reflectance imagery (e.g., when the impacts of invasives are restricted to or begin beneath the top of the canopy, cloud cover); however, radar data suffer from other difficulties, such as lower signal-to-noise ratio and the need for more sophisticated post-processing approaches [47]. Light detection and ranging (LiDAR) can also be used to approximate aboveground biomass and monitor changes in forest structure [13]. One benefit of SAR over LiDAR is that the spatial extent and temporal resolutions of SAR data are typically more comprehensive than for LiDAR, but can provide a pathway for the more detailed LiDAR data to be scaled up [48]. Efforts to monitor HWA highlight the need for such data and how different RS technologies can be used to overcome a variety of barriers. Research exploring the use of RS for HWA monitoring as well as our recent experiences working with both researchers and practitioners highlight the need for species composition data, use of a diversity of satellite sensors, and field data that can be easy to integrate with RS products.

\section{Case Study: Hemlock Woolly Adelgid}

The establishment and spread of HWA have led to a concerning decline of the keystone species, Eastern Hemlock (Tsuga canadensis), across 19 states in the eastern U.S. HWA was introduced to the Eastern U.S. from Japan in the early 1900s, likely through the transport of infested nursery stock. First discovered in Virginia, HWA has since spread from Georgia to Maine in the east and as far west as Michigan [49]. This poppyseed-sized aphid-like insect feeds on the sap of the Eastern and Carolina hemlock (Tsuga caroliniana) trees and leads to gradual decline over multiple years. Defoliation typically advances from the lower canopy to the top of the canopy [13]. The dense evergreen canopy of hemlock trees creates forests with deep shade and provides habitat for over 120 vertebrate species and approximately 90 bird species [50,51]. Hemlocks are the most shade-tolerant tree in much of their range and typically the only conifer capable of perpetuating itself. These trees play a key role in maintaining streamflow and water cycling [52], and can cool down the streams they surround, providing favorable conditions for certain fish species like trout [51]. In the northern U.S., HWA produce two lifecycles each year which overlap in the Spring [53]. In its native range, one of the HWA lifecycles will include a flying stage where the insect spreads to spruce trees for reproduction. However, in the eastern U.S., these winged insects do not have a spruce host and therefore do not survive [53-55]. The insects spread by wind, animals, and crawling between branches. With no natural predators in the eastern U.S., the main factor influencing the population of HWA is mainly low winter temperatures below -20 degrees Celsius, although there are signs of the insect becoming more tolerant of extreme cold temperatures [56]. Elevation, slope, soil moisture, terrain shape index, and aspect have been shown to impact the health of infested trees and rate of decline [53]. 


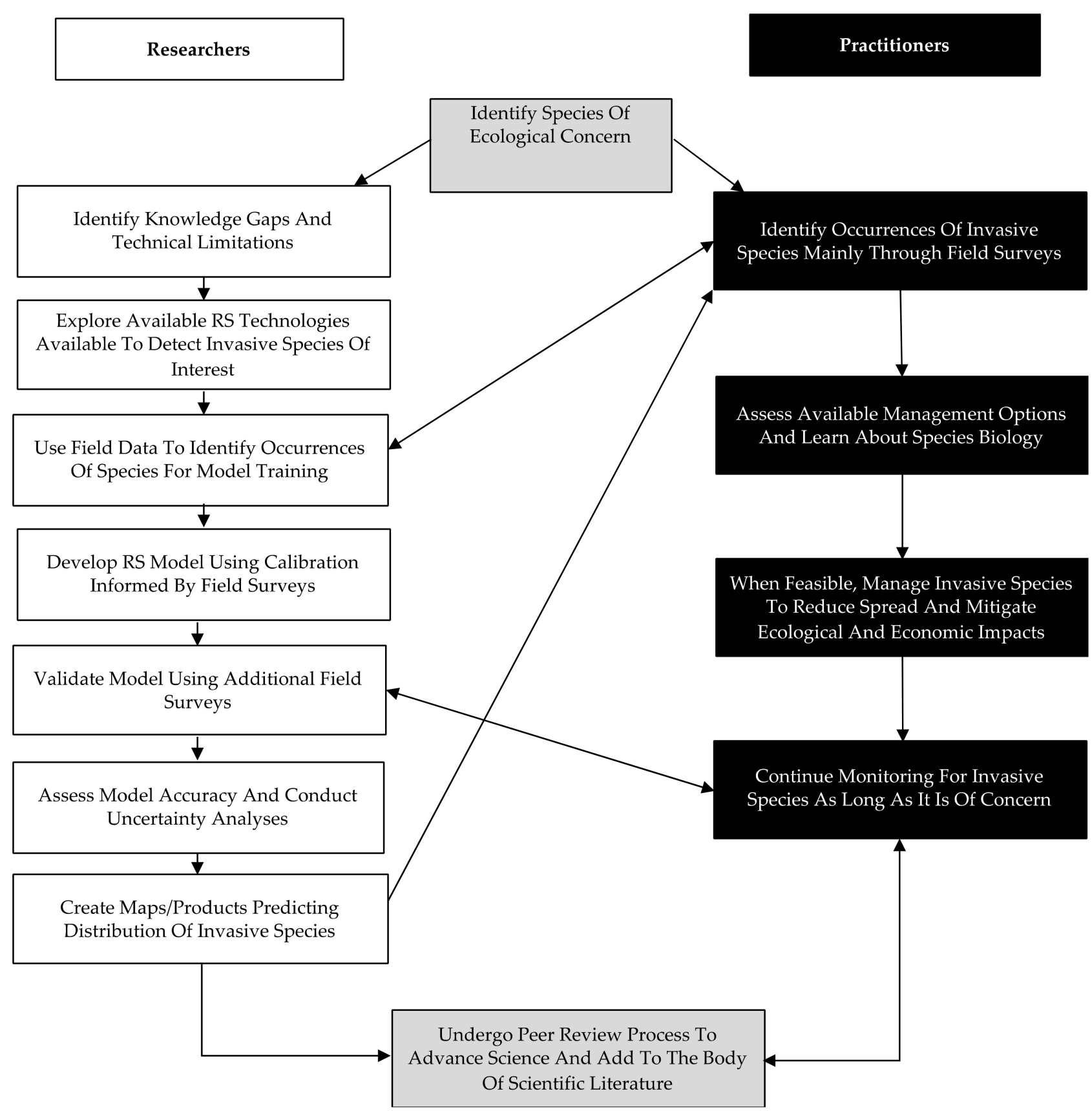

Figure 1. Simplified workflow used by RS researchers to map invasive species and their impacts (left) and practitioner's workflow to locate and manage invasive species (right). Double sided arrows indicate steps in each group's workflow where researcher-practitioner collaboration could effectively advance the objectives of both groups.

Locating HWA can be particularly tricky because of the insect's small size, limited mobility, and habit of attaching to the base of hemlock needles. The terrain that hemlocks occupy is often rugged, steep, and difficult to traverse. Furthermore, in the northern part of its range where hemlock is most abundant, many stands are in fairly remote locations. To improve monitoring of the spread of HWA, modeling and RS approaches have been applied $[10,20,21]$. However, there is currently no standard protocol for monitoring HWA from satellite imagery or in the field and, to our knowledge, practitioners typically do not leverage RS products to assist their monitoring and management efforts. Invasive species practitioners most often collect simple presence-absence data in preparation for chemical treatment of a stand, but in some instances the intensity of the infestation might be quantified to gauge the imminence and magnitude of potential tree mortality. However, the 
spatial scales and protocols used to assess stand health and infestation intensity can vary among practitioners and their field crews. For example, the New York State Department of Environmental Conservation field crews collect data on crown health measuring crown density and crown loss on a six-point scale as well as density of infestation. In contrast, the New York State Hemlock Initiative (NYSHI) measures canopy decline on a five-point scale which represents between $20 \%$ and $80 \%$ canopy loss. Both NYSHI and the Catskill Regional Invasive Species Partnership (CRISP) measure the density of HWA egg sacs to determine infestation density. However, NYSHI does so on a five-point scale by looking at the number of egg sacs on $9 \mathrm{~cm}$ of twig terminals and CRISP uses a four-point scale of infestation density measured by the terminal $5 \mathrm{~cm}$ of twigs. By necessity, the sampled twigs are often lower in the canopy where they are easily accessible by field crews. The utility of these surveys for RS model development is also highly variable (see discussion below).

Many widely used protocols lack explicit instructions on the level of survey effort that should be dedicated to a respective site. As a result, even when the same survey protocol is used by a large proportion of the practitioner community, the level of survey intensity and resulting potential for pest detection can be inconsistent. These inconsistencies can make it challenging for the RS community to integrate field data into model development. Georeferenced point data of species presence can allow researchers to focus on specific RS pixels. However, depending on the pixel size of the RS imagery used, each pixel can contain numerous trees of different tree species and this within-pixel heterogeneity can greatly confound image interpretation. To alleviate these discrepancies, practitioners could take a more unified approach and apply the same survey methods across field crews that includes georeferenced information on canopy condition and composition. The standards set by the Forest Inventory and Analysis (FIA) program are a great example of how distributed groups of field crews across a large geographic area can collect data using the same protocols and produce what is essentially the world's premier forest inventory datasets. The uniform methodologies applied by the FIA field crews is an example of how highly coordinated practitioner survey efforts produce datasets that are beneficial to researcher and practitioner communities [57,58].

In 2014, CRISP assessed the impacts of HWA on forest stands across the Catskill Mountains in New York State by evaluating the health of 45-60 random hemlock trees in plots 4-66 ha in size (containing thousands of trees) and assigning them to one of four different infestation categories: healthy, moderate, in decline, or severe decline. Because of resource and time constraints, this relatively diffuse survey approach is a fairly typical field protocol for practitioners but can limit its utility to RS researchers. A single Landsat pixel can contain over 30 trees and many of the stands contained hundreds of pixels with each stand containing a mixture of hemlocks and deciduous trees. Hemlock habitat and HWA infestation patterns provide even more challenges to monitoring for early detection of HWA. Hemlocks can occur in mixed forest stands with several other tree species. These mixed stands can be particularly challenging for detecting hemlock decline because the signal can be muted by co-occurring trees not affected by HWA (e.g., maples, beech, birch), especially when using data with relatively coarse spatial resolution. This challenge becomes even greater when the canopy is dominated by deciduous trees, obscuring the view of hemlocks from satellite images. HWA feeds on the stored starches in hemlocks, causing desiccation, discoloration, needle loss, branch die-off and eventual tree death [59]. It can take several years for the infestation to progress to limb die-off and 10-20 years for a hemlock to fully succumb to HWA infestation [46]. The tree damage from HWA infestation often begins at the bottom of the canopy and slowly progresses to the top after a long period of decline. Thus, the capacity of early detection using surface reflectance alone is limited, especially when using relatively coarse-resolution imagery where other tree species co-occur with hemlock [54]. In Figure 2, we highlight the complexities introduced by stand and pixel heterogeneity. Even when dead trees are present, the surface reflectance 
signal from the dead trees can be muted by the surrounding healthy trees. However, as the spatial resolution of the imagery increases, capacity to detect decline also increases.

Hyperspectral imagery (HSI) - typically retrieved from sensors mounted to airplanes rather than satellites-collects surface reflectance data for hundreds of narrow bands across the spectrum of visible and infrared light, thereby providing much higher spectral resolution than sensors such as Landsat or Sentinel-2. HSI is and has been used to map stress for ash (Fraxinus spp.) trees impacted by the invasive emerald ash borer (Agrilus planipennis) and hemlock trees impacted by HWA [60-62]. HSI can detect decreases in chlorophyll and water in foliage, both of which are related to increasing physiological stress [63]. In the Catskill region of New York, HSI was used to predict hemlock decline with $85 \%$ accuracy [60]. However, the measured decline was not specific to HWA infestation and could be from other causes. These methods could still be useful to monitor hemlock decline even before there are visual signs in the field, providing practitioners with specific sites in decline to monitor in the field for infestation. However, HSI data can be costly to obtain and, has limited temporal resolution as data are only available for the dates the flight took place.

Some of the RS methods discussed thus far (e.g., Landsat, Sentinel-2) are passive, meaning that they use natural light energy to measure reflectance. Active RS technologies such as LiDAR and SAR emit their own energy and measure the energy returned [64]. LiDAR provides a three-dimensional reconstruction of forest and surface structure. LiDAR is particularly useful to monitor early HWA infestations as it collects data from the entire structure of the tree canopy, not just on the top of the canopy like other satellites instruments measuring surface reflectance. Previous studies have used LiDAR data from open-source databases supported by NASA and the U.S. National Ecological Observatory Network, Global Ecosystem Dynamics Investigation (GEDI) and National Ecological Observatory Network (NEON), respectively to monitor HWA by looking at changes in forest structure as needles and branches die off $[13,65]$. Through this use of LiDAR, researchers found that HWA infestation was visible in the midstory while the canopy continued to grow [13]. Others also used LiDAR data to monitor a patch of hemlock trees where HWA was the only major contributor to decline. The author's first located hemlock in mixed forests to help separate HWA infestation from other types of decline [12]. HWA monitoring highlights how different approaches can be used to monitor invasive species depending on the approach, budget, and level of technical training. 


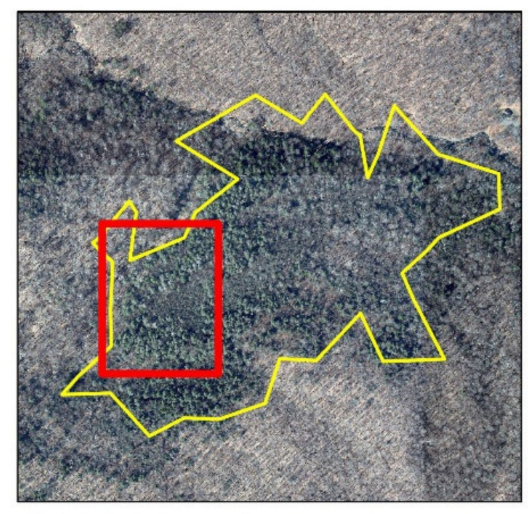

2016 Orthoimagery
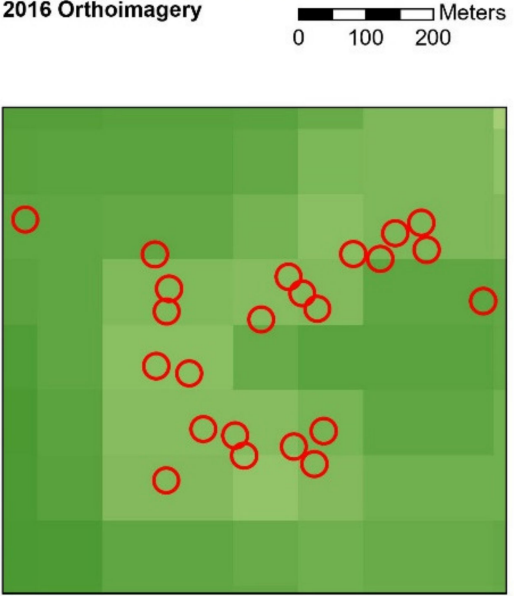

2020 Landsat NDVI

Stand in Severe Decline

Dead Hemlock

NDVI Value

High : 0.998755

Low : 0

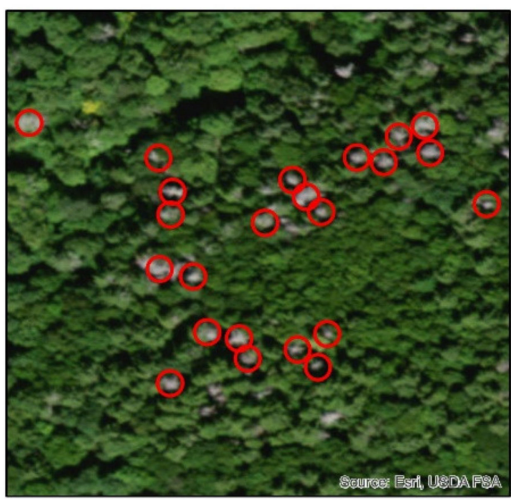

2020 NAIP

Meters

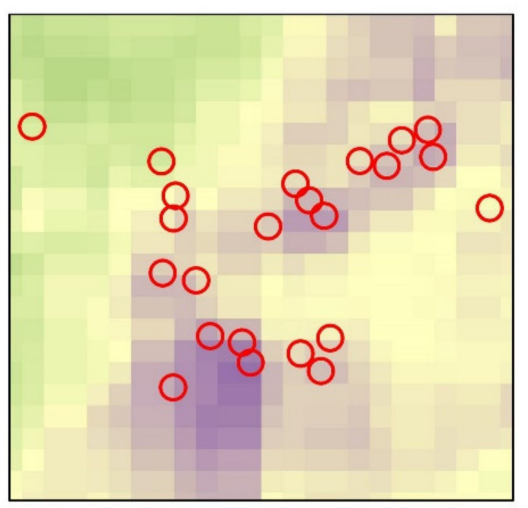

2021 Sentinel NDVI
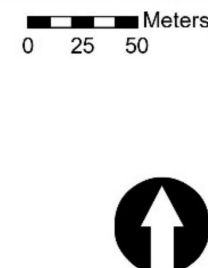

Figure 2. Imagery of a declining hemlock stand in the Catskill Mountains in New York. The leaf-off orthoimage (top left) highlights the spatial heterogeneity of the distribution of hemlocks (i.e., green conifers) throughout the stand (top left). The zoomed-in insets indicate the distribution of dead hemlock trees (red circles) within the stand using National Agriculture Imagery Program (NAIP) imagery (top right) and differences in the capacity of NDVI from $30 \mathrm{~m}$ Landsat imagery (bottom left) and $10 \mathrm{~m}$ Sentinel-2 imagery to detect forest decline.

\subsection{Restoration and Regeneration}

Once a hemlock tree succumbs to HWA, they are often replaced by native hardwood species such as black birch (Betula lenta) as well as other invasive species like the tree of heaven (Ailanthus altissima) [66]. Tree of heaven is also a host for yet another invasive species, the spotted lanternfly (Lycorma delicatula). This can create an invasive species cascade whereby HWA allows a native tree to be replaced by an invasive tree, which in turn can promote the spread of another invasive forest pest. Treatment, eradication, or host death are not always the final phase of invasive species management efforts. Measuring the success of restoration efforts can also be an important use of RS products, but despite some studies demonstrating the potential for RS technologies to benefit these efforts, application of RS for this purpose is currently uncommon. In our review of the literature, practitioners point to the lack of long-term studies assessing restoration efforts as an important factor limiting advances in restoration strategies. In one review, the authors found that $51 \%$ of in situ restoration studies evaluated the efficacy of restoration efforts by monitoring native species regeneration for only a year or less [37]. The field data collected was also 
limited in scale, most plots being $<1 \mathrm{~m}^{2}$. This scale limits the potential for RS use of data as well as relevancy to practitioners who generally manage lands on a much larger spatial scale. Being able to measure the response of an ecosystem to treatments used by practitioners on a large scale could be valuable and is starting to be used. RS topology data has been used to improve accuracy of seed firing, using drones to release seeds in mass, reforestation efforts [67] and can be used to assess vegetation regeneration following restoration treatment [40]. There is a clear benefit of researcher-practitioner collaborations to meet the challenges of invasive species like HWA, but there are relatively few examples in the literature that depict these successes. One example of an invasive species that has great potential for researcher-practitioner collaboration is the invasive tree saltcedar (Tamarix spp.), which has been the focus of a variety of publications that range from mapping and assessing the distribution of saltcedar [68-71] to review papers written with the goal of facilitating the use of different RS tools by practitioners [72].

Case Study: Saltcedar (Tamarix spp.)

Saltcedar was initially introduced to the U.S. in the 1800s for windbreak, shade, soil erosion control, and ornamental uses, but has become a problematic weed in the Southwestern U.S. [73]. The first reports of the genus escaping from cultivation date back to the 1870s. Construction of dams, diversions, and storage facilities along rivers in the 1900s reduced the summer high flows leaving behind alluvial bars and increased salinity in riparian systems, making them unsuitable for native vegetation and favoring the salt tolerant and dense saltcedar [74]. The estimated area of saltcedar went from 4000 ha in the early 1900s to between 0.5 to 0.8 million ha in 2000 [74-77]. Initially saltcedar was believed to be beneficial to riparian systems as the dense root system aids in stabilizing lake edge soils and can desalinate soils. However, stabilizing channels will make the banks more rigid which can lead to channel restriction and increase the potential and severity of floods. From 1941 to 1979 the mean width of the Brazos River in Texas was reduced from 155 to $66 \mathrm{~m}$, increasing the number of floods as well as the area impacted by floodwater. As the water recedes, saltcedar stems shoots are deposited even further down the system and can begin to root, perpetuating the cycle [78].

Approaches to restoring native ecosystems impacted by saltcedar invasion are varied and include intense chemical treatments, biocontrol using insects, replanting of native species, and scheduled dam releases. RS has been used to assess some of these restoration efforts. One study used a combination of ground and aerial surveys with MODIS satellite imagery to monitor the regeneration of native trees in the Colorado River Delta. Using Flow data in combination with NDVI values from 1992 through 2002, the authors discovered a positive relationship between NDVI and number of years with winter flooding [40]. This along with field counts of native tree species and their estimated ages suggests that allowing for winter flooding could promote growth of native trees. Some researchers using Landsat found that the saltcedar leaf beetle (Diorhabda carinulata), which has been introduced to control saltcedar, disperse depending on density and connectivity of saltcedar shrubs [40]. Other researchers have used MODIS and in situ sap flow sensors to measure evapotranspiration and calculate water budgets in a restoration plot where native cottonwood (Populus fremontii) had been planted [79]. The authors of this study expressed that their methods could be used to help practitioners understand the irrigation needs of planted cottonwoods to ensure their survival in restoration plots that have been impacted by saltcedar, but it is unclear if it has been implemented by practitioner groups.

\subsection{Role of Students and Universities}

Undergraduate and graduate students, as well as the programs training them, can play a key role in bridging the divide between practitioners and researchers. The diverse interests and career objectives of PhD students and the state of the job market for researchers requires students to obtain technical skills and conceptual knowledge in a variety of domains [80]. In a study of over $700 \mathrm{PhD}$ recipients in the physical sciences, many respondents echoed that there was little support for them in pursuing a career out- 
side of academia. When asked to rank the quality of graduate training they received in different skill sets throughout their graduate program, $43 \%$ and $76 \%$ reported low quality training in interdisciplinary work and management skills, respectively, while $68 \%$ and $62 \%$, respectively, reported that those skills are of high importance to their current career [81]. Most PhD students in the U.S. do not end up in tenured academic positions. In a survey of currently employed physical and agricultural sciences U.S. PhD recipients between 1973 and 2010, only 36\% and 43\%, respectively, were working academic jobs in 2010 [82]. Encouraging dissertation committees to include practitioners (when relevant) can help students navigate their career path while also building networks across the divide. Students will get the opportunity to learn the terminology and skill sets of both groups, preparing them to collaborate with both once they complete their studies [33]. It also enables graduate students to see first-hand how the research they do is used to solve ecological problems. Encouraging the inclusion of practitioners in the doctoral training process can ensure that grad students finish their PhDs feeling confident in their training, having built diverse networks and opened more career opportunities while being better equipped to study and solve the problems that threaten our forests.

Departments that want to broaden their curriculum and research mission to make them more applied or broadly relevant to society may benefit from creating incentives for cross disciplinary work. This could mean developing graduate or undergraduate courses where students can experience working with practitioners [83], and collect data for longterm studies, which can help alleviate some of the funding constraints associated with long-term studies. Formal acknowledgement of students whose work has been used by practitioners to solve ecological problems could also provide incentive for collaboration [33]. Internship or grant opportunities offered by universities and funding agencies can open the door for collaborative opportunities as well. Another benefit of including graduate students in the process of bridging gaps between researchers and practitioners is their ability to incorporate social media and networking to build and sustain collaborations and to disseminate research findings to the public, which is more important than ever [84]. Many forestry programs have close ties to industry professionals and other practitioners and may serve as a good example for how PhD programs in ecology and RS science can integrate practitioner communities.

Working with both researchers and practitioners can also open more opportunities for student funding [30]. Extra funding opportunities are a benefit for all groups, but graduate students often face increased financial pressure. Collaborations may create new opportunities for funding from government sources such as the National Science Foundation, the U.S. Department of Agriculture, and the Department of Defense as well as state/municipal and institutional sources, especially at institutions that incentivize cross-disciplinary applied studies [30].

\section{Discussion}

\subsection{Lessons Learned from Researcher-Practitioner Collaborations}

Our review of the literature highlights both the need for and importance of researcherpractitioner collaboration as a means to develop more robust remote sensing models and to enhance the applicability of these RS tools to practitioners. Our team of researchers and practitioners co-authoring this paper collectively represent academic institutions, the U.S. Forest Service, and nonprofit organizations. We came together through a combination of serendipity, the common need for funding, and shared concerns over the ecological impacts of HWA. Our collective goals were to (1) quantify the spatial distribution of HWA across the Catskill and Adirondack regions of New York State (i.e., the northern front of HWA expansion) and (2) improve early detection capacities. Because of the funding sources supporting this work, we needed to take a highly collaborative approach that focused on developing products to substantively improve the capacity of practitioners to monitor and manage HWA. As is common practice in stakeholder engagement efforts [85], this process began with extensive dialogue to enable our researchers to better understand the needs 
of practitioners and their metrics of "success" and to enable our practitioners to better understand the capacity of satellite RS to meet their needs and the limitations of these technologies. These conversations resulted in several key takeaways (Box 1) that, in our experience, are highly relevant to a wide range of researcher-practitioner collaborations involving application of RS technologies to assessments of forest health.

Box 1. Key Takeaways from Researcher-Practitioner Collaboration.

1. Some practitioner groups may rely on volunteeers or interns for much of their field data collection. These practitioner groups often also have limited resources and/or access to staff with specialized training in acquiring and analyzing RS imagery and data products. This is a major barrier to the integration of sophisticated RS approaches described in the scientific literature into practitioner monitoring and management efforts. As such, there is a real need for easily replicated RS products and workflows that rely on freely available data and tools. Ease of replication is essential to keep these RS approaches consistent, and to prevent wasted efforts from one-off case studies or applications. Practitioners would benefit from the ability to update these products over time as new imagery becomes available and without commissioning RS researchers.

2. Satellite RS imagery is often more efficient at detecting the evidence of invasive species rather than the invasive species itself. For example, in the case of HWA, RS products can detect areas of declining forest health likely related to an HWA infestation, but not the insect itself. This was highly informative to the practitioner community and provided a better understanding of both the capacity and limitations of these technologies. This highlights the importance of clear communication regarding what can actually be detected versus what needs to be inferred indirectly by RS analyses.

3. RS products are only as good as the field data used to calibrate and validate the resultant models. Resources for research are often quite limited, and this can be especially true for research focused on ecological applications. However, we found there to be real synergistic opportunities through collaborations between researchers and practitioners. Practitioners regularly send crews to field sites to assess a variety of attributes related to detection of invasive species and characterizations of the ecological impacts of these invasive species. However, as our researchers learned, the methods used by field crews may not be consistent across the different organizations conducting these surveys and the types of data being collected, while suitable for practitioner objectives, can be of limited use for the development of RS models. For example, practitioners might characterize infestation or forest health metrics at a stand scale, which can be much larger than the spatial resolution of the RS imagery used by researchers. Because these stands typically exhibit a high degree of spatial heterogeneity, a single stand-level metric often does not provide the spatial resolution necessary for pairing with RS imagery. A similar scale mismatch occurs when field data refer to individual trees, which are typically much smaller than satellite RS spatial resolution; thus the problem can exist in either of two ways.

4. Metrics of "success" can vary considerably between researchers and practitioners. As we discussed earlier, field-based surveys are the most commonly used approach by practitioners to map the distribution of invasive species. These surveys are the most effective way to find the actual organism of concern (e.g., the poppyseed-sized HWA can be physically observed). However, in the words of the practitioners on our team, this approach "is a bit like throwing darts in the dark" and has a low success rate at finding new occurrences, particularly for emerging pests. As such, easy to use RS products that can identify the locations of hemlock trees (in the case of HWA) and areas where stands might be in a state of decline can greatly improve the efficacy and efficiency of their mapping and monitoring efforts. This is out of step with metrics of "success" typically used by the scientific community and can result in the scientific community overlooking important RS approaches that can significantly benefit practitioner communities.

In light of these key takeaways in Box 1, our team of researchers has begun developing RS products based entirely on freely available imagery. These products include models predicting (1) the distribution of hemlock trees, which has greatly improved the targeting of practitioner field surveys and (2) areas where these hemlock trees appear to be in a state of declining health. We have worked together to amend the field data collection protocols of practitioners to improve the capacity of their field surveys (which are being conducted regardless) to contribute to the development and validation of the RS models our researchers are working on. While this is an ongoing effort, we have found thus far that this approach has greatly increased the efficiency of resource use, improved the capacity of practitioners to find previously unknown occurrences of HWA, and generated field data on causes of forest decline that are being used to refine our RS models. Our goal is to develop (1) a parsimonious field sampling protocol that balances efficiency with collecting the data most important for model development and validation and (2) a version of our model rooted in datasets easily accessible through web portals such as ClimateEngine.org and that can be run by practitioners with basic GIS training. 


\subsubsection{Workshops and Stakeholder Meetings}

Workshops that bring together different stakeholders can be a powerful tool for advancing collaborations, exchanging ideas and knowledge, and providing technical training in RS and GIS tools. Providing an overview of necessary field and RS data, workflow, and analyses that are performed can help fill in knowledge gaps that practitioners may have [86]. In return, practitioners could collect the necessary field data and provide biological information on species of interest and indicate species of concern. This could include training in the use of free software such as Climate Engine, Google Earth Engine, and QGIS, and introduction to free and open-source software communities such as Pangeo (https:/ / pangeo.io accessed on 22 August 2021), so that practitioners with limited resources can conduct analyses independently. This would be facilitated by creating GUI interfaces that improve accessibility for practitioners. Routine webinars or annual conferences can also be useful to discuss developments in technology, emerging invasives, and data needs. Ideally these workshops, meetings, and conferences would encourage networking and bring together researchers and practitioners for projects.

Once collaborations begin, regular meetings with management groups, interested stakeholders, and researchers throughout each phase of a project may be useful to assess next steps, keep all parties informed of progress, and allow discussion on what resources are available for the next phase of the project. In our experience, routine meetings with stakeholders, practitioners, and researchers were invaluable, and provided researchers with the opportunity to acquire targeted field data and guidance on how to move forward most effectively. Members of our team were offered access to land for monitoring efforts and useful monitoring tools such as drones. In addition, we gained valuable knowledge of the surrounding area and locations of the target invasive species. Regular meetings are essential for fostering new and maintain existing collaborations, and these collaborations in turn bring their own sets of benefits and challenges.

\subsubsection{The Importance of Field Data for Remote Sensing}

In order to effectively capture the signal of an invasive species and its impacts on a landscape, RS studies need to be planned based on the ecology of an invasive species, and particularly, the spatial, spectral, and temporal characteristics of its ecological impacts. Additionally, to be useful for management purposes, RS studies also need to meet the logistical goals and constraints of practitioners in the field. Lastly, RS researchers should temper their ideal data needs with the constraints of the available sensors with respect to their spatial, temporal, and spectral resolutions. In this sense, applied RS studies must balance three sets of constraints: those defined by the detectable expression of the invasive species' ecology; availability of data from practitioners in the field that can be integrated in the RS model; and by the RS instruments being utilized.

The current abundance of publicly available airborne NEON and satellite (NASA, USGS, European Space Agency, etc.) data enables RS researchers to choose data sources and instruments that best meet the demands of invasive species ecology and the needs of practitioners. This selection process should not be seen as a trivial part of the process since the selection of a sensor/system can have a substantial impact on the resulting analyses. However, no matter which sensor or data source is chosen, nearly all studies rely on field data to isolate the signal of an invasive species from the background components of the environment $[87,88]$. In an ideal world with no limitations, these field data would be detailed enough to enable accurate monitoring of an invasive at a scale, frequency, and spatial resolution that allows for a timely response by practitioners.

To facilitate or improve collaborations between researchers and practitioners, we compiled what we perceive to be an ideal list of field variables (Table 1) to be collected that would lay the groundwork for an applied RS study of an invasive species. These field variables are meant to provide the basis for RS studies to isolate a unique, remotely detectable signal of an invasive species — and related impacts on forest health-and to track its presence and/or progression across a region of interest. These variables are 
assumed to be collected at the plot scale to provide the basis for upscaling to a wider region. The optimal scale of data collection will vary between sensors and projects. In Table 1, we also assign levels of difficulty to implementing these measurements in the field and provide examples of potential challenges. Many RS products are highly sensitive to Leaf Area Index (LAI) [17] and as such having data related to this and other canopy metrics are highly informative to the RS model-building process. While there are many ways to collect data on LAI and other canopy metrics, the forest ecology community has used hemispherical photographs and image processing software (e.g., the freely available Gap Light Analyzer [89]) for decades. The biggest obstacle in collecting these data is having access to a costly camera with a hemispherical lens. If practitioners had the necessary tools, collecting these images as part of their field surveys could be a relatively easy way to build an archive of data that can be more readily integrated in RS products while providing historical data for practitioners. Future endeavors to develop centralized hubs to archive and process these images at low to no cost, could a be instrumental in revolutionizing the ways in which practitioners and researchers collaborate and benefit from each other's areas of expertise and resources.

\subsubsection{Engaging with Civic Ecologists and Community-Based Monitoring Programs}

Early detection and rapid response (EDRR) efforts are limited by the number of experts and natural resource professionals available for extensive monitoring and detection efforts. In addition, it is hard to predict what the next exotic invasive threat to our natural resources might look like. For example, Emerald Ash Borer was first detected near Detroit Michigan in 2002, but it had probably been in the area for nearly a decade [90].

Researchers and practitioners are beginning to recognize the value of mobile apps, online databases, and community-based monitoring programs (CBM) especially if they can help track and respond to issues of common community concern [91]. Environmental educators are also recognizing the value of web-based informatics tools such as eBird, iNaturalist, and Nature Atlas to enhance student engagement and learning [92]. Biodiversity apps are particularly useful in urban areas where species occurrence data is often lacking [93]. Researchers have used iNaturalist data to learn more about the distribution of certain phyla such as echinoderms and even to predict how urbanization will impact bat populations [94,95]. Some museums are even using iNaturalist data to augment reptile and amphibian museum collections for research [96]. Emerging ecological disasters caused by exotic invasive plants, pests, and or pathogens often spread at rates faster than current detection methods can keep pace with much less set up an effective eradication program (e.g., EAB example above) [92,97]. The Center for Invasive Species and Ecosystem Health Monitoring has developed a variety of apps focused on different geographical regions that can be used to report sightings of invasive species. Most of these apps are based in the U.S. and include the Great Lakes Early Detection Network, Texas Invaders, Southeast Early Detection Network, and Alaska Weeds ID. IveGot1, Outsmart Invasive Species, and EDD Maps are other examples of local civic engagement apps where individuals can report sightings of invasive species in Florida, Massachusetts, and Ontario, respectively. The European Union's Joint Research Centre has also developed an invasive species app called Invasive Alien Species Europe. Other apps such as Map of Life are available for individuals to gather biodiversity data by recording sightings of plant and animal species across the globe. PlantNet and eBird are apps used to help identify and record the presence of different plant and bird species worldwide.

Several web- or app-based informatics tools have emerged over the last couple of decades that can be used to monitor the spatial distribution of invasive species (Table 2). However, there are possible disadvantages of using some of these tools especially if the data are collected by untrained civic ecologists. These disadvantages include varying levels of protocol uniformity, need for simplified sampling designs and strong coordination and the need for advanced statistical tools to analyze the data [98]. Lack of protocol uniformity between collectors is likely the most difficult factor to overcome if researchers and land 
practitioners are to use the information. The other factors mentioned are more easily dealt with especially if researchers and practitioners work with community-based monitoring groups to train volunteers and conduct error analysis of the data collected [99]. Regardless of the data source (expert or non-expert) error analysis is a standard component of the scientific method.

Earth observation projects integrating RS platforms benefit from data collected by civic ecologists through image interpretation and collection of in situ data, both of which are useful for calibration and validation of RS imagery [100]. RS projects can take advantage of in situ data collected by non-experts as long as the app or database includes information on where and when the data was collected, as well as the experience level of the observer. While it is possible to mine existing publicly available data sets to help with calibration and validation of RS projects it may be more effective to utilize existing methodologies found in web- or app-based informatics tools to organize a community-based monitoring project focused on the area of interest for the project. Some apps like the Healthy Trees Healthy Cities app (https:/ / healthytreeshealthycitiesapp.org/; accessed on 22 August 2021) have modules that were derived from scientific methods developed for RS-based projects (e.g., Health Check module). Project management dashboards often allow administrators to assign an area of interest for a project and invite users to become a part of a targeted project. This can provide a level of organization necessary for targeted projects while leveraging existing networks, protocols, and training resources.

Our practitioner team members have highlighted a few additional things this community considers when using an app intended for monitoring invasive species. Many of the app's users will be civic ecologists, so up-to-date and comprehensive instructions in the form of an instructional guide that includes the potential uses of the app are important. Regular updates are useful, but especially those that implement feedback from app users. Accessibility is also vital. With limited resources, an app would need to be free or low cost and function on major operating systems like Android and iOS. Additionally, it would be necessary for an app to function offline, since often there is no service in rural areas where data may be collected. Finally, collected data is most useful if can be readily downloaded or exported.

\subsubsection{Open Data}

One consistent need we have found is for improved communication of new RS tools from researchers to practitioners. Generally, keeping up with the constantly evolving peer-reviewed scientific literature is out of the scope of work and time constraints for practitioners. Only one-third of 500 surveyed land managers and restoration experts managing invasive species consulted scientific literature to make management decisions [101]. To address the divide, the Journal of Applied Ecology has begun publishing a section that focuses on practitioner's perspectives. Communicating about new RS tools becomes even more difficult when scientific literature describing these tools is blocked behind a journal's paywall, which some researchers may have access to through their institutions, but practitioners may not. Paywalls disproportionately impact researchers in the Global South as well [102]. Writing a synopsis of a scientific publication or publishing in openaccess journals (e.g., Remote Sensing) can be a simple ways to make new RS tools more accessible usable to practitioners [103]. Additionally, the practitioners we have partnered with have suggested that researchers accompany publications with a technical report for better integration.

Traditionally within the geosciences, hard-won field datasets have been kept by individual researchers or small laboratory workgroups and shared on an as-needed basis (or not at all). With the rise of data and code storage and sharing technologies such as Dropbox, Google Drive, and GitHub, it is now logistically straightforward to make even large geospatial datasets more readily available. However, a culture of data protectiveness still exists, and furthermore, large-scale data sharing is hampered by lack of coordinated indexing and cataloging efforts to facilitate data discovery and accessibility. Many funding 
agencies and journals are requiring researchers to increase the amount of data that is readily accessible, which we anticipate will begin to change research culture and encourage better exchange of information. Any discipline that would claim the adjective 'scientific' must facilitate experimental replication, and since geospatial data processing workflows are often complex and nuanced, it is vitally important that not only are data shared, but that their characteristics are documented in a uniform metadata format, and that processing lineage and provenance are preserved. The Spatio Temporal Asset Catalog (STAC, https:/ / stacspec.org/; accessed on 22 August 2021) is one approach to capturing geospatial data characteristics, processing history, and use considerations, while providing a common, programmatically accessible standard for data indexing, search, and discovery. This framework is free and open-source software, and licensed under Apache v 2.0, and can thus be used both within academia and by practitioners (and indeed anyone) around the world. In combination with free code version control and sharing technologies such as git (e.g., used with github.com), researchers and practitioners can replicate workflows, extend to new locations, and fork and modify code to suit their specific needs, without starting from scratch each time, thus maintaining consistency.

Table 1. A list of field variables that could facilitate collaborations between researchers and practitioners tackling complex problems like those posed by invasive species detection, monitoring, and management. Collection methods are color-coded based on the difficulty of the methods required for data collection and challenges for implementation (i.e.: green = easy, quick, and cheap; red = requires expertise, lengthy, expensive). The color scale is: green $<$ yellow $<$ orange $<$ red, in order of least to most challenging to implement.

\begin{tabular}{|c|c|c|c|c|c|}
\hline Metrics & Field Variables & Benefit to RS & Collection Methods & $\begin{array}{l}\text { Challenges for } \\
\text { Implementation }\end{array}$ & $\begin{array}{l}\text { Typically } \\
\text { Measured? }\end{array}$ \\
\hline $\begin{array}{l}\text { Location } \\
\text { and Date }\end{array}$ & $\begin{array}{l}\text { Latitude, longitude, } \\
\text { date, and time }\end{array}$ & $\begin{array}{l}\text { Spatially and } \\
\text { temporally explicit } \\
\text { measurements. }\end{array}$ & GPS receiver & $\begin{array}{l}\text { Some expertise and } \\
\text { equipment required. }\end{array}$ & Yes \\
\hline \multirow[b]{2}{*}{ Structure } & Tree height & $\begin{array}{l}\text { Accounts for } \\
\text { variation in heights } \\
\text { between field plots } \\
\text { that can affect RS } \\
\text { signals. }\end{array}$ & Hypsometer & $\begin{array}{l}\text { Some expertise and } \\
\text { equipment required. }\end{array}$ & No \\
\hline & $\begin{array}{l}\text { Leaf angle } \\
\text { distribution }\end{array}$ & $\begin{array}{l}\text { Provides context for } \\
\text { the reflectance of } \\
\text { vegetation and serves } \\
\text { as a key parameter } \\
\text { for measuring other } \\
\text { vegetation metrics } \\
\text { with RS, such as LAI. }\end{array}$ & Field assessment & $\begin{array}{l}\text { High expertise and } \\
\text { time-consuming. }\end{array}$ & No \\
\hline \multirow{5}{*}{ Composition } & Tree species & $\begin{array}{l}\text { Provides context for } \\
\text { the reflectance of } \\
\text { vegetation and the } \\
\text { composition of the } \\
\text { RS signal. }\end{array}$ & Field assessment & $\begin{array}{l}\text { Some expertise and } \\
\text { time required. }\end{array}$ & $\begin{array}{l}\text { Not generally done } \\
\text { for hemlock surveys }\end{array}$ \\
\hline & $\begin{array}{c}\text { Relative Leaf } \\
\text { Chlorophyll Content }\end{array}$ & $\begin{array}{l}\text { Provides context for } \\
\text { the reflectance of } \\
\text { vegetation and } \\
\text { common RS indices } \\
\text { such as NDVI. }\end{array}$ & $\begin{array}{l}\text { Laboratory } \\
\text { assessment }\end{array}$ & $\begin{array}{l}\text { High expertise, } \\
\text { time-consuming, and } \\
\text { equipment required. }\end{array}$ & \multirow{4}{*}{ Not regularly taken } \\
\hline & \multirow{3}{*}{ Background/Landcover } & \multirow{3}{*}{$\begin{array}{l}\text { Accounts for } \\
\text { variation in } \\
\text { landscape } \\
\text { composition. }\end{array}$} & Field assessment & $\begin{array}{c}\text { Relatively easy to } \\
\text { acquire. }\end{array}$ & \\
\hline & & & $\begin{array}{l}\text { Spectrometer (highly } \\
\text { detailed) }\end{array}$ & $\begin{array}{l}\text { High expertise, } \\
\text { time-consuming, and } \\
\text { expensive equipment } \\
\text { required. }\end{array}$ & \\
\hline & & & $\begin{array}{l}\text { Satellite data } \\
\text { products }\end{array}$ & $\begin{array}{c}\text { Some expertise } \\
\text { required. }\end{array}$ & \\
\hline
\end{tabular}


Table 1. Cont.

\begin{tabular}{|c|c|c|c|c|c|}
\hline Metrics & Field Variables & Benefit to RS & Collection Methods & $\begin{array}{c}\text { Challenges for } \\
\text { Implementation }\end{array}$ & $\begin{array}{c}\text { Typically } \\
\text { Measured? }\end{array}$ \\
\hline \multirow{7}{*}{ Condition } & $\begin{array}{c}\text { Canopy } \\
\text { Transparency } \\
\text { and/or } \\
\text { Crown Vigor }\end{array}$ & $\begin{array}{l}\text { A measure of foliage } \\
\text { gain/loss. }\end{array}$ & $\begin{array}{c}\text { Field assessment } \\
\text { Hemispherical } \\
\text { photography }\end{array}$ & $\begin{array}{l}\text { Some expertise } \\
\text { required. } \\
\text { Some expertise and } \\
\text { equipment required. }\end{array}$ & \multirow{5}{*}{ Sometimes } \\
\hline & LAI & $\begin{array}{l}\text { A measure of foliage } \\
\text { gain/loss. }\end{array}$ & $\begin{array}{l}\text { LAI Plant Canopy } \\
\text { Analyzer }\end{array}$ & $\begin{array}{l}\text { High expertise and } \\
\text { expensive equipment } \\
\text { required. }\end{array}$ & \\
\hline & \multirow{3}{*}{ Mortality } & \multirow{3}{*}{$\begin{array}{l}\text { A binary measure of } \\
\text { the impacts of an } \\
\text { invasive. }\end{array}$} & $\begin{array}{l}\text { Hemispherical } \\
\text { photography }\end{array}$ & $\begin{array}{l}\text { Some expertise and } \\
\text { equipment required. }\end{array}$ & \\
\hline & & & Field assessment & $\begin{array}{l}\text { Relatively easy to } \\
\text { acquire. }\end{array}$ & \\
\hline & & & Aerial survey & $\begin{array}{l}\text { High expertise and } \\
\text { expense required. }\end{array}$ & \\
\hline & $\begin{array}{l}\text { Presence (and ideally, } \\
\text { absence) of the } \\
\text { invasive }\end{array}$ & $\begin{array}{l}\text { A binary measure of } \\
\text { invasive occurrence. }\end{array}$ & Field assessment & $\begin{array}{l}\text { Some expertise } \\
\text { required. }\end{array}$ & Yes \\
\hline & $\begin{array}{l}\text { Abundance of the } \\
\text { invasive }\end{array}$ & $\begin{array}{c}\text { A continuous } \\
\text { measure of invasive } \\
\text { occurrence. }\end{array}$ & Field assessment & $\begin{array}{l}\text { Some expertise } \\
\text { required. }\end{array}$ & Yes \\
\hline
\end{tabular}

Table 2. Some available apps for monitoring forest health and occurrences of invasive species.

\begin{tabular}{|c|c|c|c|}
\hline App Name & Description & User Groups & Platforms \\
\hline Healthy Trees Healthy Cities & $\begin{array}{l}\text { Health check module tracks } \\
\text { tree health using } \\
\text { non-stressor-specific } \\
\text { symptoms. Pest check module } \\
\text { records signs and symptoms } \\
\text { of pests. }\end{array}$ & $\begin{array}{l}\text { Civic Ecologists, Scientists, } \\
\text { Land Managers }\end{array}$ & Apple, Android, Web \\
\hline iMapInvasives & $\begin{array}{l}\text { Tracks invasive species and } \\
\text { management efforts. }\end{array}$ & $\begin{array}{l}\text { Civic Ecologists, Scientists, } \\
\text { Land Managers, Land Owners }\end{array}$ & Apple, Android, Web \\
\hline Forest Tree Diagnosis & $\begin{array}{l}\text { Decision support tool for } \\
\text { identifying signs and } \\
\text { symptoms of common pests } \\
\text { and diseases of economically } \\
\text { important tree species in the } \\
\text { eastern U.S. }\end{array}$ & $\begin{array}{c}\text { Foresters, Landowners, Land } \\
\text { Managers }\end{array}$ & Android \\
\hline EDD MapS & $\begin{array}{l}\text { Mapping system for } \\
\text { documenting invasive species } \\
\text { and pest distribution. }\end{array}$ & $\begin{array}{l}\text { Civic Ecologists, Educators, } \\
\text { Land Managers, Conservation } \\
\text { Biologists }\end{array}$ & Apple, Android, Web \\
\hline Wild Spotter & $\begin{array}{l}\text { Engaging and empowering } \\
\text { the public to help find, map, } \\
\text { and prevent invasive species } \\
\text { in America's wilderness areas. }\end{array}$ & Civic Ecologists & Apple, Android \\
\hline Inaturalist & $\begin{array}{l}\text { Record and share observations } \\
\text { of plants and animals. }\end{array}$ & Civic Ecologists/Scientists & Apple/Android \\
\hline
\end{tabular}

\section{Conclusions}

Invasive species mapping and restoration models are only as good as the field data used for training and validation. We argue that partnerships between researchers and practitioners are mutually beneficial and critical to addressing the pressing and complex threats that invasive species pose to forest ecosystems. To facilitate these collaborations, we provided a suite of recommendations and best practices of how these groups can work together for each other's mutual benefit but acknowledge that this is far from comprehensive. These benefits include additional funding which may help lengthen the study 
duration, increase resources for field data collection, and/or allow for the use of RS data with higher spatial, temporal, or spectral resolution. Maximizing the tools and resources that we have as invasive species researchers and forest ecologists can optimize our ability to learn more about the ecological impacts of invasive species and combat their spread. In addition, increasing the number and level of researcher-practitioner partnerships focused on invasive species detection and management will also help in this regard.

For best practices, researchers can consult practitioners in the field to identify their concerns and questions, work together to develop standardized field data collection methods which can be easily integrated and shared for data archives, select the best tools to answer their specific questions, and maximize their efforts while saving resources and learning more about the targeted species. Using open-source data and software and adding indexed data to online data banks for archive can help improve long-term studies, save financial resources, and help inform future studies. Graduate students, and the design of $\mathrm{PhD}$ training programs, can be helpful in bridging this gap and encouraging the next generation to do the same. Through these collaborations, graduate students will receive training in research while gaining firsthand experience in how research gets used to solve ecological problems. Collectively, this will enable universities to produce new generations of researchers and practitioners that are better equipped to study and solve the complicated problems that threaten our forests, while diversifying the career opportunities available to those with doctoral degrees [33].

Many scientific papers state that they hope their research can help inform practitioners or provide methodologies for practitioners, but to truly do that, there needs to be more consideration of the gap between these communities and greater effort put into closing it. By forming partnerships, researchers can gain greater access to the field data that is critical to the development of RS products and practitioners gain access to state-of-the-art tools that can allow them to allocate more resources to management and treatment of invasive species rather than detection and mapping.

Author Contributions: Conceptualization, K.P., A.E., P.B., R.A.H., J.E.T., Z.S., J.B. and A.B.R.; data curation, K.P., A.E. and P.B.; formal analysis, J.E.T. and Z.S.; project administration, K.P. and A.B.R.; resources, R.A.H. and Z.S.; supervision, K.P. and A.B.R.; validation, P.B.; visualization, K.P., A.E., R.A.H., J.E.T., J.B. and A.B.R.; writing—original draft, K.P., A.E., P.B., R.A.H. and A.B.R.; writingreview and editing, K.P., A.E., P.B., R.A.H., J.E.T., Z.S., J.B. and A.B.R.. All authors have read and agreed to the published version of the manuscript.

Funding: This research was supported by funding from The Fund for Lake George, The New York State Department of Environmental Conservation Invasive Species Program (DEC-C00972GG3350000), and New York State via a subcontract from the Cary Institute of Ecosystem Studies (DEC-01-C01205GG-3350000). The opinions, results, findings, and/or interpretations of data contained in this manuscript do not necessarily represent the opinions, interpretations, or policy of our funding sources.

Institutional Review Board Statement: Not applicable.

Informed Consent Statement: Not applicable.

Data Availability Statement: Not applicable.

Conflicts of Interest: The authors declare no conflict of interest.

\section{References}

1. di Castri, F. On invading species and invaded ecosystems: The interplay of historical chance and biological necessity. In Biological Invasions in Europe and the Mediterranean Basin; Di Castri, F., Hansen, A.J., Debussche, M., Eds.; Monographiae Biologicae; Springer: Dordrecht, The Netherlands, 1990; Volume 65, pp. 3-16, ISBN 978-94-010-7337-0.

2. Meyerson, L.A.; Mooney, H.A. Invasive Alien Species in an Era of Globalization. Front. Ecol. Environ. 2007, 5, 199-208. [CrossRef]

3. Hulme, P.E. Trade, Transport and Trouble: Managing Invasive Species Pathways in an Era of Globalization. J. Appl. Ecol. 2009, 46, 10-18. [CrossRef]

4. Seebens, H.; Blackburn, T.M.; Dyer, E.E.; Genovesi, P.; Hulme, P.E.; Jeschke, J.M.; Pagad, S.; Pyšek, P.; Winter, M.; Arianoutsou, M.; et al. No Saturation in the Accumulation of Alien Species Worldwide. Nat. Commun. 2017, 8, 14435. [CrossRef] [PubMed] 
5. Mooney, H.A.; Cleland, E.E. The Evolutionary Impact of Invasive Species. Proc. Natl. Acad. Sci. USA 2001, 98, 5446-5451. [CrossRef] [PubMed]

6. $\quad$ Lovett, G.M.; Weiss, M.; Liebhold, A.M.; Holmes, T.P.; Leung, B.; Lambert, K.F.; Orwig, D.A.; Campbell, F.T.; Rosenthal, J.; McCullough, D.G.; et al. Nonnative Forest Insects and Pathogens in the United States: Impacts and Policy Options. Ecol. Appl. 2016, 26, 1437-1455. [CrossRef]

7. Aukema, J.E.; Leung, B.; Kovacs, K.; Chivers, C.; Britton, K.O.; Englin, J.; Frankel, S.J.; Haight, R.G.; Holmes, T.P.; Liebhold, A.M.; et al. Economic Impacts of Non-Native Forest Insects in the Continental United States. PLoS ONE 2011, 6, e24587. [CrossRef] [PubMed]

8. Holcombe, T.; Stohlgren, T.J.; Jarnevich, C. Invasive Species Management and Research Using Gis; National Wildlife Research Center: Fort Collins, CO, USA, 2007; Volume 8.

9. Andrew, M.E.; Ustin, S.L. Habitat Suitability Modelling of an Invasive Plant with Advanced Remote Sensing Data. Divers. Distrib. 2009, 15, 627-640. [CrossRef]

10. Jones, C.; Song, C.; Moody, A. Where's Woolly? An Integrative Use of Remote Sensing to Improve Predictions of the Spatial Distribution of an Invasive Forest Pest the Hemlock Woolly Adelgid. For. Ecol. Manag. 2015, 358, 222-229. [CrossRef]

11. Hanavan, R.P.; Pontius, J.; Hallett, R. A 10-Year Assessment of Hemlock Decline in the Catskill Mountain Region of New York State Using Hyperspectral Remote Sensing Techniques. J. Econ. Entomol. 2015, 108, 339-349. [CrossRef] [PubMed]

12. Kantola, T.; Lyytikäinen-Saarenmaa, P.; Coulson, R.; Holopainen, M.; Tchakerian, M.; Streett, D. Development of Monitoring Methods for Hemlock Woolly Adelgid Induced Tree Mortality within a Southern Appalachian Landscape with Inhibited Access. IForest Biogeosci. For. 2016, 9, 178-186. [CrossRef]

13. Boucher, P.; Hancock, S.; Orwig, D.; Duncanson, L.; Armston, J.; Tang, H.; Krause, K.; Cook, B.; Paynter, I.; Li, Z.; et al. Detecting Change in Forest Structure with Simulated GEDI Lidar Waveforms: A Case Study of the Hemlock Woolly Adelgid (HWA; Adelges Tsugae) Infestation. Remote Sens. 2020, 12, 1304. [CrossRef]

14. Bradley, B.A. Remote Detection of Invasive Plants: A Review of Spectral, Textural and Phenological Approaches. Biol. Invasions 2014, 16, 1411-1425. [CrossRef]

15. Royle, D.D.; Lathrop, R.G. Discriminating Tsuga Canadensis Hemlock Forest Defoliation Using Remotely Sensed Change Detection. J. Nematol. 2002, 34, 213-221.

16. Williams, J.P.; Hanavan, R.P.; Rock, B.N.; Minocha, S.C.; Linder, E. Influence of Hemlock Woolly Adelgid Infestation on the Physiological and Reflectance Characteristics of Eastern Hemlock. Can. J. For. Res. 2016, 46, 410-426. [CrossRef]

17. Asner, G.P.; Scurlock, J.M.O.; A. Hicke, J. Global Synthesis of Leaf Area Index Observations: Implications for Ecological and Remote Sensing Studies: Global Leaf Area Index. Glob. Ecol. Biogeogr. 2003, 12, 191-205. [CrossRef]

18. Senf, C.; Seidl, R.; Hostert, P. Remote Sensing of Forest Insect Disturbances: Current State and Future Directions. Int. J. Appl. Earth Obs. Geoinform. 2017, 60, 49-60. [CrossRef] [PubMed]

19. Rajah, P.; Odindi, J.; Mutanga, O. Feature Level Image Fusion of Optical Imagery and Synthetic Aperture Radar (SAR) for Invasive Alien Plant Species Detection and Mapping. Remote Sens. Appl. Soc. Environ. 2018, 10, 198-208. [CrossRef]

20. Fitzpatrick, M.C.; Preisser, E.L.; Porter, A.; Elkinton, J.; Ellison, A.M. Modeling Range Dynamics in Heterogeneous Landscapes: Invasion of the Hemlock Woolly Adelgid in Eastern North America. Ecol. Appl. 2012, 22, 472-486. [CrossRef] [PubMed]

21. Pontius, J.; Hallett, R.; Martin, M.; Plourde, L. A Landscape-Scale Remote Sensing/GIS Tool to Assess Eastern Hemlock Vulnerability to Hemlock Woolly Adelgid-Induced Decline. 15. Gen. Tech. Rep. 2010, 802, 657-671.

22. Pasquarella, V.; Bradley, B.; Woodcock, C. Near-Real-Time Monitoring of Insect Defoliation Using Landsat Time Series. Forests 2017, 8, 275. [CrossRef]

23. Resasco, J.; Hale, A.N.; Henry, M.C.; Gorchov, D.L. Detecting an Invasive Shrub in a Deciduous Forest Understory Using Late-fall Landsat Sensor Imagery. Int. J. Remote Sens. 2007, 28, 3739-3745. [CrossRef]

24. Dukes, J.S.; Pontius, J.; Orwig, D.; Garnas, J.R.; Rodgers, V.L.; Brazee, N.; Cooke, B.; Theoharides, K.A.; Stange, E.E.; Harrington, R.; et al. Responses of Insect Pests, Pathogens, and Invasive Plant Species to Climate Change in the Forests of Northeastern North America: What Can We Predict?This Article Is One of a Selection of Papers from NE Forests 2100: A Synthesis of Climate Change Impacts on Forests of the Northeastern US and Eastern Canada. Can. J. For. Res. 2009, 39, 231-248. [CrossRef]

25. Royimani, L.; Mutanga, O.; Odindi, J.; Dube, T.; Matongera, T.N. Advancements in Satellite Remote Sensing for Mapping and Monitoring of Alien Invasive Plant Species (AIPs). Phys. Chem. Earth Parts ABC 2019, 112, 237-245. [CrossRef]

26. Ahmed, N.; Atzberger, C.; Zewdie, W. Integration of Remote Sensing and Bioclimatic Data for Prediction of Invasive Species Distribution in Data-Poor Regions: A Review on Challenges and Opportunities. Environ. Syst. Res. 2020, 9, 32. [CrossRef]

27. Malavasi, M.; Barták, V.; Jucker, T.; Acosta, A.T.R.; Carranza, M.L.; Bazzichetto, M. Strength in Numbers: Combining Multi-Source Remotely Sensed Data to Model Plant Invasions in Coastal Dune Ecosystems. Remote Sens. 2019, 11, 275. [CrossRef]

28. Hulme, P.E.; Pyšek, P.; Jarošík, V.; Pergl, J.; Schaffner, U.; Vilà, M. Bias and Error in Understanding Plant Invasion Impacts. Trends Ecol. Evol. 2013, 28, 212-218. [CrossRef]

29. The Great Divide. Nature 2007, 450, 135-136. [CrossRef]

30. Funk, J.L.; Parker, I.M.; Matzek, V.; Flory, S.L.; Aschehoug, E.T.; D’Antonio, C.M.; Dawson, W.; Thomson, D.M.; Valliere, J. Keys to Enhancing the Value of Invasion Ecology Research for Management. Biol. Invasions 2020, 22, 2431-2445. [CrossRef]

31. Pettorelli, N.; Laurance, W.F.; O’Brien, T.G.; Wegmann, M.; Nagendra, H.; Turner, W. Satellite Remote Sensing for Applied Ecologists: Opportunities and Challenges. J. Appl. Ecol. 2014, 51, 839-848. [CrossRef] 
32. Michener, W.K.; Jones, M.B. Ecoinformatics: Supporting Ecology as a Data-Intensive Science. Trends Ecol. Evol. $2012,27,85-93$. [CrossRef]

33. Courter, J.R. Graduate Students in Conservation Biology: Bridging the Research-Implementation Gap. J. Nat. Conserv. 2012, 20, 62-64. [CrossRef]

34. Pettorelli, N.; Safi, K.; Turner, W. Satellite Remote Sensing, Biodiversity Research and Conservation of the Future. Philos. Trans. R. Soc. B Biol. Sci. 2014, 369, 20130190. [CrossRef] [PubMed]

35. Matzek, V.; Pujalet, M.; Cresci, S. What Managers Want from Invasive Species Research Versus What They Get. Conserv. Lett. 2015, 8, 33-40. [CrossRef]

36. Frazier, A.E.; Wang, L. Characterizing Spatial Patterns of Invasive Species Using Sub-Pixel Classifications. Remote Sens. Environ. 2011, 115, 1997-2007. [CrossRef]

37. Kettenring, K.M.; Adams, C.R. Lessons Learned from Invasive Plant Control Experiments: A Systematic Review and MetaAnalysis: Invasive Plant Control Experiments. J. Appl. Ecol. 2011, 48, 970-979. [CrossRef]

38. Home I ForWarn, II. Available online: https:/ / forwarn.forestthreats.org/ (accessed on 3 September 2021).

39. Duro, D.C.; Coops, N.C.; Wulder, M.A.; Han, T. Development of a Large Area Biodiversity Monitoring System Driven by Remote Sensing. Prog. Phys. Geogr. Earth Environ. 2007, 31, 235-260. [CrossRef]

40. Nagler, P.L.; Hinojosa-Huerta, O.; Glenn, E.P.; Garcia-Hernandez, J.; Romo, R.; Curtis, C.; Huete, A.R.; Nelson, S.G. Regeneration of Native Trees in the Presence of Invasive Saltcedar in the Colorado River Delta, Mexico. Conserv. Biol. 2005, 19, 1842-1852. [CrossRef]

41. Müller, J.; Opgenoorth, L. On the Gap between Science and Conservation Implementation-A National Park Perspective. Basic Appl. Ecol. 2014, 15. [CrossRef]

42. Royle, D.D. Monitoring Hemlock Forest Health in New Jersey Using Landsat TM Data and Change Detection Techniques. For. Sci. 1997, 43, 327-335.

43. Orwig, D.A.; Foster, D.R.; Mausel, D.L. Landscape Patterns of Hemlock Decline in New England Due to the Introduced Hemlock Woolly Adelgid. J. Biogeogr. 2002, 29, 1475-1487. [CrossRef]

44. Rentch, J.; Fajvan, M.A.; Evans, R.A.; Onken, B. Using Dendrochronology to Model Hemlock Woolly Adelgid Effects on Eastern Hemlock Growth and Vulnerability. Biol. Invasions 2009, 11, 551-563. [CrossRef]

45. Pontius, J.A.; Hallett, R.A.; Jenkins, J.C. Foliar Chemistry Linked to Infestation and Susceptibility to Hemlock Woolly Adelgid (Homoptera: Adelgidae). Environ. Entomol. 2006, 35, 112-120. [CrossRef]

46. Rosenthal, J.; Wildova, R. Relating Eastern Hemlock (Tsuga canadensis) Ecosystem Services to Stand Attributes in the Catskills. 2017. Available online: http:/ /www.monitoringash.org/wp-content/uploads/2018/03/ERI-hemlock-report-for-CRISP-2017.pdf (accessed on 25 August 2021).

47. Ghulam, A.; Porton, I.; Freeman, K. Detecting Subcanopy Invasive Plant Species in Tropical Rainforest by Integrating Optical and Microwave (InSAR/PolInSAR) Remote Sensing Data, and a Decision Tree Algorithm. ISPRS J. Photogramm. Remote Sens. 2014, 88, 174-192. [CrossRef]

48. Kaasalainen, S.; Holopainen, M.; Karjalainen, M.; Vastaranta, M.; Kankare, V.; Karila, K.; Osmanoglu, B. Combining Lidar and Synthetic Aperture Radar Data to Estimate Forest Biomass: Status and Prospects. Forests 2015, 6, 252-270. [CrossRef]

49. Ellison, A.; Orwig, D.; Fitzpatrick, M.; Preisser, E. The Past, Present, and Future of the Hemlock Woolly Adelgid (Adelges Tsugae) and Its Ecological Interactions with Eastern Hemlock (Tsuga Canadensis) Forests. Insects 2018, 9, 172. [CrossRef]

50. Ward, J.S.; Montgomery, M.E.; Onken, B.P.; Cowles, R.S. Eastern Hemlock Forests: Guidelines to Minimize the Impactsof Hemlock Woolly Adelgid; Connecticut Agricultural Experiment Station: New Haven, CT, USA, 2004; p. 32.

51. Jonas, S.Z.; Xi, W.; Waldron, J.D.; Coulson, R.N. Impacts of Hemlock Decline and Ecological Considerations for Hemlock Stand Restoration Following Hemlock Woolly Adelgid Outbreaks. Tree For. Sci. Biotechnol. 2012, 6, 22-26.

52. Brantley, S.; Ford, C.R.; Vose, J.M. Future Species Composition Will Affect Forest Water Use after Loss of Eastern Hemlock from Southern Appalachian Forests. Ecol. Appl. 2013, 23, 777-790. [CrossRef] [PubMed]

53. Havill, N.P.; Vieira, L.C.; Salom, S.M. Biology and Control of Hemlock Woolly Adelgid; Connecticut Agricultural Experiment Station: New Haven, CT, USA, 2016; p. 29.

54. McClure, M.S. Biological Control of Hemlock Woolly Adelgid in the Eastern United States; USDA, Forest Service, Forest Health Technology Enterprise Team: Morgantown, WV, USA, 2001.

55. Reardon, R.; Onken, B.; Cheah, C.; Montgomery, M.E.; Salom, S.; Parker, B.L.; Costa, S.; Skinner, M. Biological Control of Hemlock Woolly Adelgid; Forest Health Technology Enterprise Team: Morgantown, WV, USA, 2004.

56. Costa, S.D.; Trotter, R.T.; Montgomery, M.; Fortney, M. Low Temperature in the Hemlock Woolly Adelgid System; US Forest Service, Forest Health Technology Enterprise Team: Morgantown, WV, USA, 2008.

57. Bechtold, W.A.; Patterson, P.L. The Enhanced Forest Inventory and Analysis Program-National Sampling Design and Estimation Procedures; U.S. Department of Agriculture, Forest Service, Southern Research Station: Asheville, NC, USA, 2015; p. SRS-GTR-80.

58. Tomppo, E.; Gschwantner, T.; Lawrence, M.; McRoberts, R.E. National Forest Inventories: Pathways for Common Reporting; Springer Science \& Business Media: Berlin/Heidelberg, Germany, 2009; ISBN 978-90-481-3233-1.

59. Havill, N.P.; Montgomery, M.E.; Yu, G.; Shiyake, S.; Caccone, A. Mitochondrial DNA from Hemlock Woolly Adelgid (Hemiptera: Adelgidae) Suggests Cryptic Speciation and Pinpoints the Source of the Introduction to Eastern North America. Ann. Entomol. Soc. Am. 2006, 99, 195-203. [CrossRef] 
60. Pontius, J.; Hallett, R.; Martin, M. Using AVIRIS to Assess Hemlock Abundance and Early Decline in the Catskills, New York. Remote Sens. Environ. 2005, 97, 163-173. [CrossRef]

61. Pontius, J.; Hanavan, R.P.; Hallett, R.A.; Cook, B.D.; Corp, L.A. High Spatial Resolution Spectral Unmixing for Mapping Ash Species across a Complex Urban Environment. Remote Sens. Environ. 2017, 199, 360-369. [CrossRef]

62. Hanavan, R.P.; Hallett, R.; Pontius, J.; Cook, B. Data Fusion Techniques Using NASA Goddard's LiDAR, Hyperspectral \& Thermal Imager to Detect the Emerald Ash Borer, Agrilus Plannipenis, in New England. In Proceedings of the Entomological Society of America Annual Meeting, Portland, OR, USA, 19 November 2014.

63. Pontius, J.; Hallett, R.; Martin, M. Assessing Hemlock Decline Using Visible and Near-Infrared Spectroscopy: Indices Comparison and Algorithm Development. Appl. Spectrosc. 2005, 59, 836-843. [CrossRef] [PubMed]

64. US Department of Commerce, National Oceanic Service and Atmospheric Administration. What Is LIDAR. Available online: https: / / oceanservice.noaa.gov / facts/lidar.html (accessed on 3 September 2021).

65. Orwig, D.A.; Boucher, P.; Paynter, I.; Saenz, E.; Li, Z.; Schaaf, C. The Potential to Characterize Ecological Data with Terrestrial Laser Scanning in Harvard Forest, MA. Interface Focus 2018, 8, 20170044. [CrossRef] [PubMed]

66. Orwig, D.A.; Foster, D.R. Forest Response to the Introduced Hemlock Woolly Adelgid in Southern New England, USA. J. Torrey Bot. Soc. 1998, 125, 60-73. [CrossRef]

67. Mohan, M.; Richardson, G.; Gopan, G.; Aghai, M.M.; Bajaj, S.; Galgamuwa, G.A.P.; Vastaranta, M.; Arachchige, P.S.P.; Amorós, L.; Corte, A.P.D.; et al. UAV-Supported Forest Regeneration: Current Trends, Challenges and Implications. Remote Sens. 2021, 13, 2596. [CrossRef]

68. Narumalani, S.; Mishra, D.R.; Burkholder, J.; Merani, P.B.T.; Willson, G. A Comparative Evaluation of ISODATA and Spectral Angle Mapping for the Detection of Saltcedar Using Airborne Hyperspectral Imagery. Geocarto Int. 2006, 21, 59-66. [CrossRef]

69. Nagler, P.L.; Glenn, E.P.; Jarnevich, C.S.; Shafroth, P.B. Distribution and Abundance of Saltcedar and Russian Olive in the Western United States. Crit. Rev. Plant Sci. 2011, 30, 508-523. [CrossRef]

70. Wang, L.; Silván-Cárdenas, J.L.; Yang, J.; Frazier, A.E. Invasive Saltcedar (Tamarisk Spp.) Distribution Mapping Using Multiresolution Remote Sensing Imagery. Prof. Geogr. 2013, 65, 1-15. [CrossRef]

71. Diao, C.; Wang, L. Incorporating Plant Phenological Trajectory in Exotic Saltcedar Detection with Monthly Time Series of Landsat Imagery. Remote Sens. Environ. 2016, 182, 60-71. [CrossRef]

72. Huylenbroeck, L.; Laslier, M.; Dufour, S.; Georges, B.; Lejeune, P.; Michez, A. Using Remote Sensing to Characterize Riparia Vegetation: A Review of Available Tools and Perspectives for Managers. J. Environ. Manag. 2020, 267, 110652. [CrossRef] [PubMed]

73. Conway, K.; Sirota, J.; Rose, S. Tamarisk (Tamarix Spp.). Available online: http://www.coopext.colostate.edu/TRA/PLANTS/ index.html\#http:/ / www.colostate.edu/Depts/CoopExt/TRA/PLANTS/tamarisk.htm (accessed on 5 August 2021).

74. Di Tomaso, J.M. Impact, Biology, and Ecology of Saltcedar (Tamarix Spp.) in the Southwestern United States. Weed Technol. 1998, 12, 326-336. [CrossRef]

75. Neill, W.M. Tamarisk. Fremontia 1985, 12, 22-23.

76. Zavaleta, E. The Economic Value of Controlling an Invasive Shrub. AMBIO J. Hum. Environ. 2000, 29, 462-467. [CrossRef]

77. Dudley, T.L. Progress and pitfalls in the biological control of saltcedar (Tamarix spp.) in north america. Gen. Tech. Rep. 2005, 4, $12-15$.

78. Blackburn, W.H.; Knight, R.W.; Schuster, J.L. Saltcedar Influence on Sedimentation in the Brazos River. J. Soil Water Conserv. 1982, 37, 298-301.

79. Nagler, P.; Jetton, A.; Fleming, J.; Didan, K.; Glenn, E.; Erker, J.; Morino, K.; Milliken, J.; Gloss, S. Evapotranspiration in a Cottonwood (Populus Fremontii) Restoration Plantation Estimated by Sap Flow and Remote Sensing Methods. Agric. For. Meteorol. 2007, 144, 95-110. [CrossRef]

80. Nerad, M. It Takes a Global Village to Devel- Op the next Generation of PhDs and Postdoctoral Fellows. Acta Acad. Suppl. 2011, 2, 198-216.

81. Smith, S.J.; Pedersen-Gallegos, L.; Riegle-Crumb, C. The Training, Careers, and Work of Ph.D. Physical Scientists: Not Simply Academic. Am. J. Phys. 2002, 70, 1081-1092. [CrossRef]

82. Turk-Bicakci, L.; Berger, A.; Haxton, C. The Nonacademic Careers of STEM PhD Holders. Am. Int. Res. $2014,1-11$.

83. Duchelle, A.E.; Biedenweg, K.; Lucas, C.; Virapongse, A.; Radachowsky, J.; Wojcik, D.J.; Londres, M.; Bartels, W.-L.; Alvira, D.; Kainer, K.A. Graduate Students and Knowledge Exchange with Local Stakeholders: Possibilities and Preparation: Graduate Students and Knowledge Exchange. Biotropica 2009, 41, 578-585. [CrossRef]

84. Osterrieder, A. The Value and Use of Social Media as Communication Tool in the Plant Sciences. Plant Methods 2013, 9, 26. [CrossRef]

85. McBride, M.; Lambert, K.; Huff, E.; Theoharides, K.; Field, P.; Thompson, J. Increasing the Effectiveness of Participatory Scenario Development through Codesign. Ecol. Soc. 2017, 22. [CrossRef]

86. Palumbo, I.; Rose, R.A.; Headley, R.M.K.; Nackoney, J.; Vodacek, A.; Wegmann, M. Building Capacity in Remote Sensing for Conservation: Present and Future Challenges. Remote Sens. Ecol. Conserv. 2017, 3, 21-29. [CrossRef]

87. Kerr, J.T.; Ostrovsky, M. From Space to Species: Ecological Applications for Remote Sensing. Trends Ecol. Evol. 2003, 18, 299-305. [CrossRef] 
88. Rhodes, C.J.; Henrys, P.; Siriwardena, G.M.; Whittingham, M.J.; Norton, L.R. The Relative Value of Field Survey and Remote Sensing for Biodiversity Assessment. Methods Ecol. Evol. 2015, 6, 772-781. [CrossRef]

89. Frazer, G.W.; Canham, C.D.; Lertzman, K.P. Gap Light Analyzer (GLA), Version 2.0: Imaging software to extract canopy structure and gap light transmission indices from true-colour fisheye photographs, user's manual and program documentation; Simon Fraser University: Burnaby, BC, Canada; Institute of Ecosystem Studies: Millbrook, NY, USA, 1999.

90. Siegert, N.W.; McCullough, D.G.; Liebhold, A.M.; Telewski, F.W. Resurrected from the Ashes: A Historical Reconstruction of Emerald ash Borer Dynamics through dendrochronological Analysis; U.S. Forest Service, Forest Health Technology Enterprise Team: Morgantown, WV, USA, 2007.

91. Whitelaw, G.; Vaughan, H.; Craig, B. Establishing the Canadian Community Monitoring Network. Environ. Monit. Assess. 2003, 88, 409-418. [CrossRef] [PubMed]

92. Hardy, C.R.; Hardy, N.W. Adapting Traditional Field Activities in Natural History Education to an Emerging Paradigm in Biodiversity Informatics. Am. Biol. Teach. 2018, 80, 501-519. [CrossRef]

93. Li, E.; Parker, S.S.; Pauly, G.B.; Randall, J.M.; Brown, B.V.; Cohen, B.S. An Urban Biodiversity Assessment Framework That Combines an Urban Habitat Classification Scheme and Citizen Science Data. Front. Ecol. Evol. 2019, 7, 277. [CrossRef]

94. Michonneau, F.; Paulay, G. Using INaturalist to Learn More about Echinoderms. Reef Encount. 2015, 30, $29-31$.

95. Border, J.A.; Newson, S.E.; White, D.C.J.; Gillings, S. Predicting the Likely Impact of Urbanisation on Bat Populations Using Citizen Science Data, a Case Study for Norfolk, UK. Landsc. Urban Plan. 2017, 162, 44-55. [CrossRef]

96. Spear, D.M.; Pauly, G.B.; Kaiser, K. Citizen Science as a Tool for Augmenting Museum Collection Data from Urban Areas. Front. Ecol. Evol. 2017, 5, 86. [CrossRef]

97. Vaughan, H.; Brydges, T.; Fenech, A.; Lumb, A. Monitoring Long-Term Ecological Changes Through the Ecological Monitoring and Assessment Network: Science-Based and Policy Relevant. Environ. Monit. Assess. 2001, 67, 3-28. [CrossRef] [PubMed]

98. Kamenova, S.; Bartley, T.; Bohan, D.; Boutain, J.; Colautti, R.; Domaizon, I.; Fontaine, C.; Lemainque, A.; Le Viol, I.; Mollot, G.; et al. Invasions Toolkit: Current Methods for Tracking the Spread and Impact of Invasive Species. Adv. Ecol. Res. 2017, 56. [CrossRef]

99. Hallett, R.; Hallett, T. Citizen Science and Tree Health Assessment: How Useful Are the Data? Arboric. Urban For. 2018, 44, 236-247.

100. Fritz, S.; Fonte, C.C.; See, L. The Role of Citizen Science in Earth Observation. Remote Sens. 2017, 9, 357. [CrossRef]

101. Matzek, V.; Covino, J.; Funk, J.L.; Saunders, M. Closing the Knowing-Doing Gap in Invasive Plant Management: Accessibility and Interdisciplinarity of Scientific Research. Conserv. Lett. 2014, 7, 208-215. [CrossRef]

102. Coloma, J.; Harris, E. Open-Access Science: A Necessity for Global Public Health. PLoS Pathog. 2005, 1, e21. [CrossRef] [PubMed]

103. Walsh, J.C.; Dicks, L.V.; Sutherland, W.J. The Effect of Scientific Evidence on Conservation Practitioners' Management Decisions. Conserv. Biol. 2015, 29, 88-98. [CrossRef] [PubMed] 